\title{
On a Pilgrimage Mountain in Tea Country
}

Tropic midwinter: a shiver down the spine of the tea fields.

We lie down off the path, on the stupa's dark side:

Uncratered, smooth, lime-washed moon.

The lanterns of the pilgrims mark the way to the mountaintop, The lanterns of the stars obscure the ways into sleep.

The Buddha's footprint marks the holy rock at the summit. It is known Shakyamuni never trekked this far south.

After sunrise we wake, cold and rained-on, To pilgrims returning: laughter, bangles, tin teapots.

To banish sleep, Dharuma sliced off his eyelids.

Where he cast them, half-moons of skin, the tea plant grewGreen leaf, bud, the wealth of empires undreamt of.

When it rains, the footprint fills with rain.

When it clears, the footprint warms with sun.

Brazen St. Sparrow, self-ablaze, self-forgetful, Sips from the instep and bathes in the heel. 